\title{
A COMPARATIVE STUDY OF THE IMPACT OF DA MODELS ON THE WRITING ABILITY AND ATTITUDE OF IRANIAN EFL LEARNERS
}

\author{
Jaleh Hassaskhah and Masoumeh Javan Haghparast* \\ The University of Guilan, Rasht, \\ Iran
}

\begin{abstract}
The overall aim of this study was to advance understanding of the impact of the two main existing models of Dynamic Assessment (i.e. interventionist DA and interactionist DA) on the improvement of the writing abilities and attitudes of EFL learners. To have a viable conclusion, the study employed a quasi experimental research design in three pre-intermediate EFL classrooms, where each class functioned as both the experimental and the control groups. Then using the statistical procedure of repeated measure, the researchers obtained four sets of scores, the means of which were later calculated and compared in pairs (pair $t$-test) to see the development of students, if any, throughout the semester. Moreover, the learners' attitude towards each of the models was assessed qualitatively after the term was over. This was done through thematic analysis techniques. Based on the results of the data analysis, it was found out that of the two main existing frameworks of DA, in spite of the common claims of their proponents, none can be given priority over the other. The only difference is the situations to which they can be applied. While interventionist DA is applicable in larger classes, interactionist DA can be best used with individual learners or in classes with fewer than four or five students. This study also indicated that learners feel more satisfied with DA than the traditional testing techniques in which their individual voices are not usually heard. Students, who used DA, liked writing activities more than before and stated that internalizing the rules and techniques got easier. Consequently, although the results obtained are susceptible to some context related limitations as well, which might threaten their full generalizability; this will not prevent us from refuting the impracticality of generalizing DA to all contexts and instead suggesting it as a valuable tool of assessment for all kinds of contexts.
\end{abstract}

\footnotetext{
*jaleh_hassaskhah@yahoo.com and mj.haghparast@yahoo.com
} 
Key words: Interventionist Dynamic Assessment, Interactionist Dynamic Assessment, EFLwriting Ability

\section{INTRODUCTION}

A glance at the history of teaching and testing reveals that the two have always had an undeniable relationship. However, whereas this relationship is sometimes immediately observable in cases such as the relationship between the Audio-lingual teaching method and Discrete point tests, at other times the impact is not so immediate. A case in point are the newer communicative language teaching approaches, where the changes in teaching are more apparent than those in testing. In other words, testing is lagging behind; i.e. despite many "reforms" which have been attempted, only simple modifications were made to the existing language tests. Accordingly, Pena and Gillam (2000) claim that the room for the development of entirely new models of assessment is still open. Yet, Sternberg and Grigrenko (2002) believe that Dynamic Assessment (henceforth DA) is good enough to bridge this gap because it, unlike the other approaches in testing, helps the assessor gain a richer and more valid view of learner's abilities, even those that are still developing.

DA, grounded in Vygotsky's Sociocultural Theory of Mind (henceforth SCT), also admits a close relationship between teaching and assessment and claims that engaging individuals in activities that are mediated by others and by cultural objects allows them to develop what is described as higher forms of consciousness that are unique to humans (Vygotsky, 1978).

In spite of the reliable research conducted in ESL situations, teachers claiming that DA does not fit all size classrooms are still reluctant to apply DA in EFL contexts (Poehner, 2008). This might be due to the fact that little research has been done to scrutinize the effects of applying DA into diverse contexts, including EFL classrooms. Thus, to satisfy this need, this research work was designed to explore whether DA promotes development in EFL learners' writing ability or not and whether or not the learners' attitude towards writing will see any changes after experiencing with DA.

\section{THEORETICAL BASIS OF DA}

DA is originally rooted in Vygotsky's (1978) proposal which offered a systematic framework for investigating cognition in a social context and consequently defining how higher mental functions develop therein. From then on, it has found great significance in the field of testing and assessment. Feuerstein (cited in Poehner, 2008), for instance, believing that the framework is able to promote development while assessing learners, used the term to propose an assessment technique which had two main characteristics: 1) 
assessment and instruction cannot be separated; 2) future development is constructed (Poehner, 2008).

In general, there are two main models of DA: interventionist and interactionist, both of which have their proponents and critics. The proponents (e.g. Vygotsky, 1978; Poehner, 2007, 2008) assert that DA is "prognostic" rather than "diagnostic" (Poehner, 2008); i.e. unlike non-Dynamic Assessments, which are solely based on a sampling of observable behavior, it focuses on the hidden processes underlying a performance. Thus, it is able to inform the teacher about the way an error can be cured. Similarly, Sternberg and Grigorenko (2002) assert that DA provides more information than nonDynamic Assessments on the learner's present abilities, the abilities that are still developing and those which will develop in future. The opponents, on the other hand, blame DA for its novelty, low reliability, validity and practicality, especially in larger classes.

To clarify these views, further familiarity with both DA frameworks is required.

\section{INTERVENTIONIST DA}

Poehner (2008) defines interventionist DA as the model in which the mediators (the assessors) are not free to respond to the learner's needs as these become more apparent during the procedure, but they must instead follow a highly scripted approach to mediation in which all prompts, hints and leading questions have been arranged in advance in a hierarchical manner, from implicit to explicit. Many researchers employed this model to conduct their studies. Buddof (1987), for instance, used a framework, much like an experimental research design (pretest-treatment-post-test), whose main drawback, according to Poehner (2008), was its resemblance to non-Dynamic Assessments; the only difference was letting the students receive mediation and having another test. Thus, it was only able to explore the potential for development and did not facilitate it. To compensate for this shortcoming, Guthke (1993) incorporated mediation into the test itself to promote development. He designed a language aptitude test called "LLT", that could scarcely be adapted to other content areas. Wiedl and Carlson (1992) added a verbalization part to Guthke's LLT, in which learners were supposed to verbalize their reasons for giving an answer, so that the researchers were able to trace the cognition processes better. A good study of interventionist DA is the one done by Brown and her colleagues (1996) through which she made use of Aljaafreh and Lantolf's regulatory scale (1994, p. 471) in which hints are ordered in a standard way from the most implicit to the most explicit. This application of DA is the one that is adopted by the researchers in the present study. 


\section{INTERACTIONIST DYNAMIC ASSESSMENT}

In contrast to interventionist DA, in this approach the mediator is not tied to a script or set of rules, but he/she is required to respond according to the needs of the learners throughout the DA procedure. Here, there are usually specific tasks or tests which should be completed by the cooperation between the mediator and the learner (Poehner, 2008). Poehner (ibid.) calls Feuerstein's Mediated Learning Experience (MLE) "the most comprehensive approach to DA", because it includes innovations similar to those proposed by most other DA practitioners. Bruner (1980) enthusiastically observed, "MLE is not only for the handicapped, it is for all of us since it is MLE which makes us human!'(cited in Feuerstein et al., 1998, p.58).

As a result, the major differences between interventionist and interactionist DAs and NDA are as follows: while in non-dynamic assessment a problem may never be identified because of the lack of interaction between the student and the teacher, in DA the mediator attempts to identify the source of error. Of course, in interventionist DA the mediator is not allowed to interact with the learner in any way to resolve the problem due to the rigid framework of this approach. It is clear now (Feuerstein et al., 1988) that in an approach that permits the mediator to negotiate the mediation and where the assessment is "emergent", the mediator can be fully committed to promote development.

\section{ISSUES AND ANSWERS}

Snow (1990) argues that dynamic and non-dynamic procedures share the same theoretical understandings of abilities. Thus, he asks why one should bother to learn all its rules? But, as Poehner (2008) mentions, this is not true and he argues that human mental abilities as defined by DA are seen as emergent and thus of a modifiable nature rather than something stable.

Still, Glutting and Mc Dermot (1990) worry that interacting with the learner, during the administration of the assessment, jeopardizes test-retest reliability, in that there is no guarantee that he/she will receive the same amount of help at two points in time. They believe that learning during an assessment is a threat to the reliability of the test, because if the object of assessment (the targeted ability of the testee) changes, then it cannot be measured.

Büchel and Scharnhorst (1993) refer to the same point as the reason for the unreliability of the assessment. They argue that different performances of an individual at two points in time make the "observation" of his abilities unreliable. Elsewhere, Büchel and Scharnhorst (1993) write that evaluating individual's ability in Feuerstein's tradition is not logical, because whether the performance is the result of the mediator's contribution to the learner or not remains doubtful. 
The best answer to these types of criticisms is provided by Vygotsky (1998) who argued:

One of the major impediments to the theoretical and practical study of child development is the incorrect solution of the problem of the environment and its role in the dynamics of age, when the environment is considered as something outside with respect to the child, as a circumstance of development, as an aggregate of object conditions existing without reference to the child and affecting him by the very fact of their existence. The understanding of the environment that developed in biology as applied to evolution of animal species must not be transferred to the teaching on child development. (p. 198)

Poehner (2008) interprets the above mentioned part in this way: development can be understood through the "negotiation" that happens between "individuals" and "artifacts" to internalize the rules and strategies.

Therefore, Vygotsky's emphasis on understanding individuals rather than measuring them indicates the need to adopt new criteria for reporting and interpreting the results of dynamic procedures, because "statically-driven" notions such as reliability are not applicable to DA.

Van Lier (2004) criticizes traditional experimental research methods for degrading the context into a set of variables which can be easily added or omitted from the background against which the individual is performing. That is, NDA context is simply conceived as "accumulation of variables.... In this way, performance is isolated from contextual variables." (Poehner, 2008, p.74) Feuerstein's "transcendence" is salient in understanding this process. Transcendence emphasizes the need for variable contexts, so that the learner always feels the challenge and will not stop developing. According to Feuerstein et al. (1980), if the learner does not feel the need to progress once in the process of learning a language, he/she will stop endeavoring. Transcendence is similar to what was mentioned before as "transfer tasks" that were proposed by Vygotsky (1978). Learners are faced with increasingly complex tasks, while they are able to independently do tasks which were completed before using mediations; they still require the help of a mediator to perform new tasks. Then they will not cease developing.

Concerning the validity, some criticize DA for not having "concurrent" or "predictive" validity. Ratner (1997, p.48) argues strongly that applying these "mechanical correlations" is of no use, and a lack of correlation or a strong correlation between, for example, a newly-developed test and the other measure is not a guarantee of the validity of the test.

In the case of construct validity, DA, like other assessment approaches, should take into account a construct and aim at assessing it. This can be easily done by the tester, and thus this problem will be resolved. 
The last criticism on DA is made by researchers like Snow (1990) or Büchel and Scharnhorst (1993). Snow (1990) points out that while DA gives "richer descriptions of human cognitive performance and its responsiveness to intervention than do conventional assessments" (p. 135), it does not take measurement as its primary goal. Büchel and Scharnhorst (1993) make a similar point and argue that DA (specifically Feuerstein's methodology) is a pedagogical tool "and not an assessment tool".

The answer to these arguments is that DA is a development-referenced assessment, i.e. its success is evaluated through its impact on a learner's development.

An influential factor in dynamic assessment is the way a teacher profiles the performance of learners. The performance of learners at the beginning of a course should be recorded carefully and in a correct way, so that it could be analyzed for the mediation phase. If this process is not conducted in the right way, mediation may become useless.

To sum up, although the study of relevant DA literature reveals that DA is a moving and complex landscape, a glance at the studies in this field show that despite the considerable advantages of DA, not many teachers are eager to adopt it into their classrooms, because they see it as a threat for dominating testing techniques (Van Lier, 2006), or because it is too different (Sternberg and Grigrenko, 2002).

To validate these views, there seems to be the need for further research to remove the ambiguities, especially in the EFL context. As a result, the present study was designed to have a contribution by exploring whether DA is able to promote development in EFL learners' writing ability or not and whether or not the learners' attitude towards writing will see any changes after experiencing with DA.More specifically, the following research questions guided this research:

1. Does DA promote development in EFL learners' writing skills?

2. Is there any positive change in learners' attitude towards writing in English and their progress throughout the course of the study?

\section{METHOD}

This section provides a thorough description of what was done to take us to the answers of the questions posed by this study.

\subsection{Participants}

This study was conducted on 29 pre-intermediate level female students in the Allameh Tabatabaee Language School in Rasht, who were in the age range of 14-19 and had similar cultural backgrounds. As the study intended to compare the impact of both DA models on the EFL learners' writing ability 
and attitude, the interventionist framework, due to its nature, was used for larger classroom context with 25 students (Guthke, 1982; Carlson and Wiedle, 1992) and the interactionist for a smaller number of students with 4 students from another pre-intermediate class. In addition, the entire participant had prior training in writing, as it was part of the skills taught by their textbooksNew Headway Plus by John and Liz Soars. The Interventionist DA was conducted within the regular 90 minute classroom instructions, 15-20 minutes of which was given to the mediation; whereas the interactionist DA was exercised with 4 volunteers, in which each and every learner was taught and assessed individually. Naturally, the time and specifity of the mediation in this approach differed from those in the interventionist model where the teacher had to fit everything into the available instructional time. Finally, all of the participants, on receiving their individual reports on their development, were asked to write about how the new testing approach impacted on their feelings and attitudes towards writing itself and how they judged the extent to which it helped them improve their witing.

\subsection{Instruments}

Out of different existing genres of writing, only description was selected because this was the type which had to be taught by the teachers of that level in the research site. Using the guidelines of the sources "Advanced Grammar in Use" (Hewings, 1999), "Academic Writing Course" (Jordan, 1999) and the internet site www.thewritingsite.com, the teacher oriented the students in the first session of the course to the requirements of the genre and monitored their understanding by assigning them to write about what was expected. From then on the topics were given to the students to write about; the topics were all chosen via teacher- student negotiations. Each piece of writing was then scored based on Weigle's essay scoring criteria (2004), where students' works were evaluated for four components of content, organization, accuracy and complexity. Then an overall score was assigned to each paper by calculating the mean score of all the scores obtained on the four components of writing skill. The reliability of this scoring technique was tested by asking another qualified rater to score a sample of $25 \%$ of the papers accordingly. The interrater agreement was found to be 77.06-an acceptable index to base the analysis of the data of this study on.

Moreover, the number of hints required by each student was recorded by the researchers so that they could trace the development of the students by comparing the possible changes in the experimental period. This information was kept in the personal profile of each learner, so that it could later be used for the future teaching programs.

\subsection{Design and procedures of the study}


This study is of mixed approach nature and employed both quantitative and qualitative techniques. For the quantitative part we ran a quasi experimental design because finding parallel classes where reliable comparisons could have been made was not possible, hence in our design each class functioned as both the experimental and control groups. In the first half of the term, the learners' current writing level was assessed through 4 pieces of writing produced by the learners in this period. These four writings which were assessed without mediation and in red pen correction style were kept for further comparison after the application of DA. The second part of the study was conducted after the mid-term examination (second half of the semester). In this period, the students had chosen to watch a film and write descriptive essays based on its episodes. The film was an episodic one named "Lost"; the students received an episode before each mediation session (episodes 1-8). In each episode, the actors of the movie faced a new problem and tried to overcome it. The teacher gave them about 15-20 minutes for each mediation session. As previously mentioned, in the first half of the semester the teacher corrected the papers at home traditionally, just underlining the wrong forms and writing the correct ones. The students were provided with the instructional material if they had asked for it. But in the second half, the students had time to check their own work and correct it with the help of teacher. The means of the writing scores of the second half of the semester which were considered as the posttests scores were also calculated for comparison. Here the students were assessed once a week by DA. The writing development of the students was not only reported using a single score (the mean of the scores obtained on the four components mentioned earlier), but a detailed mediation on the specific errors was also provided by the teacher. Students were asked to save a typed copy of each of the writings to observe their own development over time. These typed copies were mailed to the teacher a day before the DA session and were corrected and given to the students after the DA session. There was an extra copy that was used in the mediation session. It should be noted that since the regular mediation sessions were considered to last for only 20 minutes of the end of the class time, if in some occasions this time was not enough, it was continued in the following session. While in the interventionist part of the study the learners were provided with standardized mediations, starting by the most implicit mediation and moving toward the most explicit one( Aljaafreh and Lantolf,1994), those in the interactionist group, were provided with the mediation whenever and whatever necessary. These learners were given as much time as it was required.

And finally for the qualitative part of the study, the researcher asked the learners to write their opinion about their own performance during the study. These comments were then thematically analyzed to show whether they felt any change in their writing knowledge, and also in their attitude toward writing 


\subsection{Data Collection and Analysis Procedure}

DA is considered superior to traditional assessment approaches, in that it takes into account the individual differences between the learners, additionally it is development-referenced. Therefore, to collect the data, the researchers asked the students to keep track of their improvements while trying to increase their contribution to the mediation. They were expected to do so by collecting the typed copies of their writings and comparing them. Moreover, commenting on their improvement and writing about their feelings during the semester was required.

To find whether DA was more effective than the traditional testing technique or not, the researchers assessed the learners, using interventionist and interactionist DA frameworks and kept track of the students' improvement throughout the administrations of assessments. SPSS software version 17.0 was used to compare the test results. However, given the $t$ - test is used for only two comparisons, and since in this study there were 7 comparisons (i.e. pretest 1 with pretest 2 , pretest 2 with pretest 3 , etc.), we had to correct for this by using Bonferroni test. So the new level of significance was set as $0143(0.01 / 7=0.0143$. Accordingly, the mean scores of the students in the first half of semester with those in the second half of the course were compared based on this new level of significance.

For the qualitative part of the study, the comments of the students (on their attitude toward writing in English and their progress) were coded by the researchers for positive change, no change, negative change or unclear response. Then, the data was analyzed carefully. It was done using thematic analysis in which some "themes" are marked within data and the data is organized in rich detail and analyzed in the light of research questions (Braun and Clarke, 2006). Primary data was interpreted using a computer software package QSR NVivo 7; also manual sorting was used as the researchers found it more creative and interpretative than computerized categorizing. In this procedure, special phrases were coded as "free nodes" and manually separated from the rest of data. These were then sorted into themes.

\section{RESULTS AND DISCUSSION}

The major purpose of the study was to investigate the impact of applying DA procedures on the possible development of EFL learners' writing ability. To do so the repeated measure statistical technique was used. The results of this analysis for the first and second half of the term appear (pre-test and post test periods) in Table 1.

As the table shows, in the first half of the term (Pretests 1 and 2, Pretests 2 and 3 and Pretests 3 and 4) there is no significant difference in the students' writing performance. The observed Sig. (2-tailed) differences in all these 
VOLUME 5

cases $(0.092,0.094$ and 0.102$)$ exceed $>0.0143$. Therefore, no development is achieved through traditional assessment. However, after the introduction of DA these figures changed and the results for all post tests (Posttests 1 and 2, Posttests 2 and 3 and Posttests 3 and 4) with the observed Sig. (2-tailed) differences of 0.000 , suggest that there is a significant difference.

Table 1. Paired differences of tests

\begin{tabular}{|l|c|c|c|c|c|}
\hline & Mean & Std. Deviation & $\begin{array}{c}\text { Std. Error } \\
\text { Mean }\end{array}$ & $\mathrm{t}$ & $\begin{array}{c}\text { Sig. (2- } \\
\text { tailed) }\end{array}$ \\
\hline Pretests 1 and 2 & -0.11000 & 0.31524 & 0.06305 & -1.745 & 0.094 \\
\hline Pretests 2 and 3 & -0.15000 & 0.42696 & 0.08539 & -1.757 & 0.092 \\
\hline Pretests 3 and 4 & -0.13000 & 0.38270 & 0.07654 & -1.698 & 0.102 \\
\hline $\begin{array}{l}\text { Pretest 4 and } \\
\text { posttest1 }\end{array}$ & -0.98000 & 0.22730 & 0.04546 & -21.557 & 0.000 \\
\hline Posttests 1 and 2 & -0.73000 & 0.24917 & 0.04983 & -14.649 & 0.000 \\
\hline Posttests 2 and 3 & -0.66000 & 0.23805 & 0.04761 & -13.863 & 0.000 \\
\hline Posttests 3 and 4 & -0.67000 & 0.23629 & 0.04726 & -14.177 & 0.000 \\
\hline
\end{tabular}

In other words, by starting the DA procedure a great development can be seen in the performance of the learners. This indicates that receiving mediation through hints is promoting development in their writing ability. The students' development over time is also shown through figure 1:

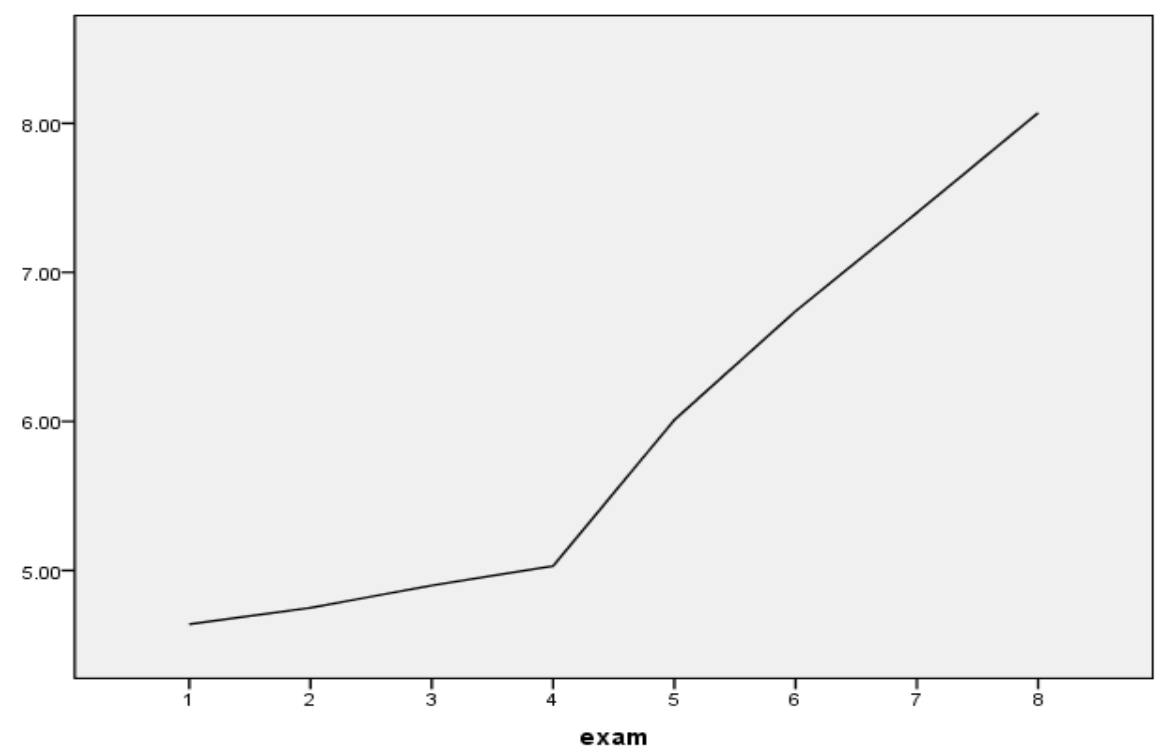

Figure 1. Students' development during the experience

As shown in the figure above, there was only a gradual development during the first half of the semester, while the learners where provided with a 
traditional assessment. This is actually the type of assessment that is used by still many teachers all over the world.

As stated earlier, in our DA assessment, the researchers kept track of the number of hints required by the learners by counting the number of hints during the second half of the semester. The change in the number of hints required by the students is shown in figure 2 by plotting the mean score of the hints provided for the learners after the mid-term session.

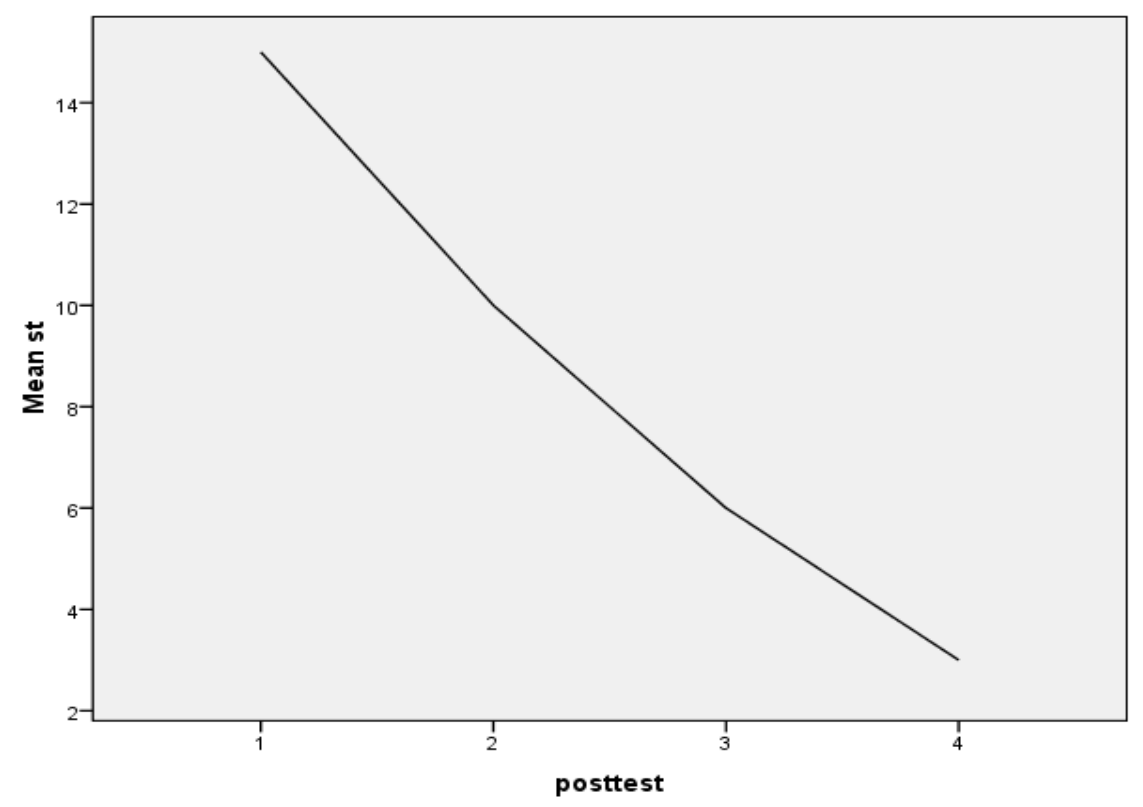

Figure 2. The mean score of hints required by the students

As illustrated by this figure, the number of hints the students required during composition writing sessions decreased gradually as they internalized more writing rules.

Regarding the qualitative part of the study, the data is divided into two parts: 1) the data representing Students' perception of change as presented in table 2 and 2) the data indicating the developmental pattern in the students' writing ability.

Table 2 indicates, in general, there is a significant perception of positive change in both areas. While $78 \%$ of the learners were satisfied with their improvement in writing strategies and 86\% thought that writing in English can be a good experience, only $4 \%$ did not like their development in writing strategies and $1 \%$ still did not like writing tasks.

Table 2. Students' perception of change 


\begin{tabular}{|l|c|c|c|c|}
\hline $\begin{array}{l}\text { Perception of change } \\
\text { in: }\end{array}$ & Positive change & Negative change & No change & $\begin{array}{l}\text { Unclear } \\
\text { response }\end{array}$ \\
\hline $\begin{array}{l}\text { Descriptive writing } \\
\text { strategies }\end{array}$ & $78 \%$ & $4 \%$ & $9 \%$ & $9 \%$ \\
\hline $\begin{array}{l}\text { Feeling toward writing } \\
\text { in English }\end{array}$ & $86 \%$ & $1 \%$ & $5 \%$ & $8 \%$ \\
\hline
\end{tabular}

The language used by learners mostly showed improved achievement. They used sentences like "...happy to have better scores..."; "writing is interesting now..." and "...satisfied with what I know now..." The phrases that the participants of both lines of the study (i.e. interventionist and interactionist) used, justifies what the proponents of DA had claimed in the literature - DA makes a great deal of positive reaction in the learners.

As for the second part of the data, the researchers analyzed the compositions of students, focusing on the type of errors they made, in the light of the mediations they asked for in each of the components identified by Weigle (2004). As an example this procedure is illustrated for the learner no. 18 with 15 yrs of age who studied in high school. She, who had a mean score of 4.8 during pretests (traditional testing phase) suffered from problems in content (did not address the topic well and showed rare use of sensory and figurative language), organization (her organizational plan could not be clearly seen and there was almost no coherence, She also used few connectors between sentences), accuracy (she made many errors regarding word choice and form and verb tenses that sometimes interfered with understanding), and finally complexity (she used a very limited range of vocabulary).

In the first mediation session, she asked for mediations 13 times: (content: 2 hints for proper use of sensory language and 3 for figurative; organization: 2 mediations for planning the composition and 2 for connectors; accuracy: 2 hints for correct use of verb tenses and 1 for word choice; complexity: 1 mediation for using new forms of words).

During the second mediation session, the learner asked for 10 mediations: (content: 3 hints for appropriate use of figurative language; organization: 1 hint for organizational plan and 3 for establishing coherence; accuracy: 2 hints for appropriate verb tenses; and complexity: 1 mediation for using new words).

In session three, the learner received 7 hints: (content: 2 hints for using figurative language; organization: 2 hints for connectors; accuracy: 2 hints for verb tenses and 1 for word choice).

In the fourth mediation session, the same learner received 6 hints: (content: 2 mediations for figurative language; organization: 1 hint for connectors; accuracy: 3 hints for verb tenses).

To conclude, Learner 18, who was a participant of the interventionist line of the study, made an average development through the study. She asked for 13 hints at the beginning of the DA sessions and 6 at the end. Her final composition and the mediations she had asked for revealed that, while she 
learned how to use sensory language effectively, she did not know how to use figurative language yet. Regarding the organization area, she could plan her composition adequately, and for the accuracy, she had problem with appropriate use of verb tenses (e.g. when to use the past perfect). Finally, she was able to use new words more effectively. A more or less similar pattern was observed for all the learners in both interventionist and interactionist frameworks.

\section{CONCLUSION}

Generally, this study indicated that DA in both frameworks proved to be efficient. Besides, students, who used DA, liked writing activities more than before and stated that internalizing the rules and techniques got easier. Consequently, this research refutes the earlier findings which claimed the impracticality of DA to all contexts, and instead suggests it as a useful way of assessment for all kinds of contexts. The findings might have implications for syllabus designers, material developers and language teachers.

First, this study may be helpful to syllabus designers who need to emphasize more flexibility. In DA, learners are the most important side of the educational program. They are treated as individuals and the teachers may take the syllabus designers' role if the syllabus is not in line with the needs of the learners. Therefore, there should be enough flexibility in the syllabi to satisfy the needs of the students.

Second, the material developers can also make use of his study. They should develop materials which can be manipulated to face the needs of the learners, give the possibility of diagnosing the problematic areas to the teachers and promote interaction between teacher and learner as much as possible.

Third, language teachers can also benefit from the results of this study. This study may give language teachers the insight that incorporating DA into the classes helps the teachers identify the weaknesses of their learners and provide mediation when and where needed. Moreover, this study gives helpful guidelines to teachers for implementing DA into their language classes. They may feel more confident when practical guidelines are provided in method section, where the teaching and assessment phases are presented step-by-step and carefully.

\section{REFERENCES}

Aljaafreh, A. and J.P. Lantolf. (1994). Negative feedback as regulation and second language learning in the zone of proximal development. The Modern Language Journal 78: 465-483.

Brown, A. and R.A. Ferrara. (1985). Diagnosing zones of proximal development. In Culture, Communication and Cognition. Vygotskian 
Perspectives. J.V. Wertsch (Ed.). Cambridge. Cambridge University Press.

Budoff, M. (1987). The validity of learning potential assessment. In Dynamic Assessment: An Interactive Approach to Evaluating Learning Potential. C.S. Lidz (Ed.). New York: Guilford.

Guthke, J. (1982). The learning test concept - An alternative to the traditional static intelligence test. The German Journal of Psychology 6 (4): 306-324.

Guthke, J. (1993). Current trends in theories and testing of intelligence. In Learning Potential Assessment: Theoretical, Methodological and Practical Issues. J.H.M Hamers, K. Sijtsma, and A.J.J.M. Ruijssenaars (Eds.). Amsterdam: Swets \& Zeitlinger.

Jordan,R.R. (1990). Academic Writing Course. London, Collins E.L.T.

Poehner, M.E. (2007). Beyond the test: L2 dynamic assessment and the transcendence of mediated learning. The Modern Language Journal 91. pp. 323-340. Poehner, M.E. (forthcoming). Both sides of the conversation: the interplay between mediation and learner reciprocity in dynamic assessment. In Sociocultural Theory and the Teaching of Second Languages. J.P. Lantolf and M.E. Poehner. (Eds.). London: Equinox.

Poehner, M. E. (2008). Dynamic Assessment: A Vygotskian Approach to Understanding and Promoting L2 Development. London: Springer.

Rea-Dickins, P. (2004). Understanding teachers as agents of assessment. Language Testing 21: 249-258.

Sternberg, R.J. and E.L. Grigorenko. (2002). Dynamic Testing. The Nature and Measurement of Learning Potential. Cambridge: Cambridge University Press.

Vygotsky, L.S. (1978). Mind in Society: The Development of Higher Psychological Processes. Cambridge, MA: Harvard University Press.

Weigle.S.C. (2004). Assessing Writing, 9, 25-27.

Wiedl, K.H., S. Schöttke, and M.D.C Garcia. (2001). Dynamic assessment of cognitive rehabilitation potential in schizophrenic persons and in elderly persons with and without dementia. European Journal of Psychological Assessment 17: 112-119. 